\title{
Lexicographical Practice and Lexicological Research: The Case of Shangani in Zimbabwe*
}

Peniah Mabaso, African Languages Research Institute (ALRI), University of Zimbabwe, Harare, Zimbabwe (penmabaso@arts.uz.ac.zw)

\begin{abstract}
The article outlines the contribution of ALRI towards the development of the minority languages in Zimbabwe, with special reference to Shangani. After a description of the status of Shangani, a brief summary of the Zimbabwean language use policy is given. The challenges for the development of lexicographical practice and lexicological research are discussed with regard to a minority language that has been marginalized for a long time. After the consideration of the kind of dictionary planned for Shangani in accordance with the user profile, the role of a dictionary in codifying and harmonizing a language is stressed. Except for contributing to the orthographic development of a language, lexicography also forms the basis for the furtherance of literacy in a community.
\end{abstract}

Keywords: ALRI, MINORITY LANGUAGES, MARGINALIZED LANGUAGES, LEXICOGRAPHICAL PRACTICE, LEXICOLOGICAL RESEARCH, DICTIONARY, TARGET USERS, SHANGANI

Opsomming: Leksikografiese praktyk en leksikologiese navorsing: Die geval van Sjangani in Zimbabwe. Die artikel skets die bydrae van ALRI tot die ontwikkeling van die minderheidstale in Zimbabwe, met spesiale verwysing na Sjangani. Na 'n beskrywing van die status van Sjangani, word 'n kort opsomming van die Zimbabwiese taalgebruiksbeleid gegee. Die uitdagings vir die ontwikkeling van leksikografiese beleid en leksikologiese navorsing word bespreek met betrekking tot ' $n$ minderheidstaal wat vir ' $n$ lang tyd gemarginaliseer is. Na ' $n$ beskouing van die soort woordeboek wat in ooreenstemming met die gebruikersprofiel vir Sjangani beplan word, word die rol van 'n woordeboek vir die kodifisering en harmonisering van 'n taal beklemtoon. Behalwe dat dit bydra tot die ortografiese ontwikkeling van 'n taal, vorm leksikografie ook die basis vir die bevordering van geletterdheid in 'n gemeenskap.

Sleutelwoorde: ALRI, MINDERHEIDSTALE, GEMARGINALISEERDE TALE, LEKSIKOGRAFIESE PRAKTYK, LEKSIKOLOGIESE NAVORSING, WOORDEBOEK, TEIKENGEBRUIKERS, SJANGANI

* This article is based on a paper presented at the Eleventh International Conference of the African Association for Lexicography, organized by the Tshivenda National Lexicography Unit, University of Venda for Science and Technology, Thohoyandou, Republic of South Africa, 5-7 July 2006. 


\section{Introduction}

Shangani, also called Tsonga in South Africa and Changana or Hlengwe in Mozambique, is categorized in the Zimbabwe Education Act 1987 as a minority language because of its number of speakers. This Act is also used as the country's language policy. During the colonial period, Shangani never had a significant role in education. The language was therefore neglected and marginalized until the 1982 consultations on the Zimbabwean languages. These consultations indicated that for most of what became to be recognized as minority languages, neglect and marginalization had had a very negative impact on their existence. The adoption of the majority languages in Zimbabwe as languages of education meant that the speakers of these neglected and marginalized languages were assimilated into the speech communities of the majority languages. The Shanganis in the Shona area came to be regarded as Shona speakers. And similarly, the Kalangas in the Ndebele area came to be considered as Ndebele speakers. So the lack of minority language use meant that many speakers also lost their ethnicity and the knowledge of their languages.

The establishment of the African Languages Research Institute (ALRI) in 2001 provided the impetus for developing the previously neglected and marginalized minority languages. The focus has been on lexicological and lexicographical research as a way of furthering the indigenous languages. Shangani is the latest to embark on this development. The delay in the development of Shangani can be explained by many impeding factors. The most important among these factors are the neglect and marginalization of the language after colonialism and the attendant language use policies in schools. Also there was no researcher at ALRI who could undertake work on the language. The lack of resources is always an important consideration in the development of minority languages.

The aim of this article is to discuss the challenges facing the furthering of lexicological and lexicographical research in minority languages like Shangani. As these challenges are numerous, the article will focus on research at ALRI and the training of lexicographers. Without these developments, the language cannot possibly contend to representation in education. Lexicography as objective at ALRI is one of the viable means to codify and harmonize the language, also to form the basis for other developments such as orthography and literacy. The fact that Shangani is also spoken in South Africa and Mozambique introduces another critical dimension to its linguistic study and the development of its lexicological and lexicographical research. Each of the countries where the language is spoken has its own orthography and agenda for development. As the work proceeds, major choices will have to be made. Not to consider Shangani language developments in countries outside Zimbabwe may end up in repeating and doubling research. Consulting with researchers in Shanganispeaking communities in neighbouring countries may entail generalizations through harmonization strategies, possibly with the loss of the specific indige- 
nous content of Zimbabwean Shangani. This situation therefore causes a dilemma for the development of Shangani, which, apart from receiving no resource allocations, also has few researchers working collaboratively on all aspects of the language.

\subsection{Who are the Shanganis?}

The Shanganis are a minority ethnic group concentrated in south eastern Zimbabwe. They are found in the southern districts of Masvingo Province, mainly Chiredzi South and Mwenezi. There are also very few numbers of them in other districts like Zaka, Masvingo South and Mberengwa. Shangani-speaking communities also reside in Southern African countries like Mozambique, South Africa and Swaziland. In Mozambique, they are referred to as the Changana or Hlengwe, while in South Africa, they are known as the Tsonga. Hachipola (1998) notes that the term Shangani is a generic name used to refer to the followers of Soshangana, who was one of Zwide's military leaders. Soshangana, a Tsonga himself, migrated northward and settled in present-day Zimbabwe. On his way to the North, Soshangana incorporated other smaller groups like the Ndau, Ngoni and Nyembeni (Hachipola 1998). As a result, Zimbabwean Shangani has a very close linguistic relationship with Tsonga spoken in neighbouring South Africa and Changana or Hlengwe spoken in Mozambique.

It can be argued that Zimbabwean Shangani is a Tsonga variety caused by historical and linguistic factors. There exists a great degree of mutual intelligibility between Tsonga and Zimbabwean Shangani which suggests a closer relationship than mere linguistic contact. Zimbabwean Shangani now has some peculiar features of phonology and vocabulary which differ from Tsonga. This is understandable as language, which is as dynamic as society itself, changes over a period of time. However, on this basis it cannot be argued that Zimbabwean Shangani should be viewed as an independent variant of Tsonga, and thus has to benefit from a specific linguistic and cultural study. Also, as the three countries where Tsonga is spoken are sovereign states with their own development policies, it is not necessarily easier to undertake mutual beneficial collaborative studies. This would only be possible when some research on Zimbabwean Shangani has been done.

\subsection{What is the status of Shangani in the respective regions?}

In Zimbabwe, Shangani is one of the country's officially recognized minority languages, spoken by around five percent of the total population. However, with its minority status, it has not benefited much since the colonial era from the Zimbabwean language policies. Although it is a language of significant presence in South Africa and Mozambique, there are no inter-border links that could promote the inter-country usage of Shangani. In South Africa, the lan- 
guage is among the country's eleven official languages and in Mozambique, where it is also well developed, it is one of the country's official national languages. On the other hand, because of particular historical circumstances, Shangani is an undeveloped minority language in Zimbabwe. This means it could not benefit from linguistic development allocations by the government. The consequences of this are unfortunate for the language. Shangani is mostly maintained in family and community circles, chiefly as a spoken language with no publications produced in it in Zimbabwe. The only written material in it consists of texts such as informal letters by literate speakers using their own orthographies. Zimbabwean Shangani lags behind in orthography mainly because it has been scantily studied by linguists. The government also paid very little attention to the development of the country's minority languages. Speakers of minority languages are forced to use either Shona or Ndebele, the national languages. As a result, most minority language speakers are bilingual. While bilingualism is an advantage in a situation where language policies do not protect or promote minority languages, they are eventually abandoned with the result that the speakers are ethnically assimilated into the speaker communities of the majority languages.

\section{Zimbabwe's current language use policy}

Zimbabwe's language use policy played a big role in subverting the development of the country's minority languages. Viriri (2003) notes that according to the wording of the Education Act these minority languages seem not to exist. The Zimbabwe Education Act of 1987, Chapter 55, which doubles as the country's language policy states that:

(a) Subject to the provisions of this section, the three main languages of Zimbabwe, namely Shona, Ndebele and English shall be taught in all primary schools from the first grade as follows:

(i) Shona and English in all areas where the mother tongue of the majority of the residents is Shona or

(ii) Ndebele and English in all areas where the mother tongue of the majority residents is Ndebele.

(b) Prior to fourth grade either of the languages preferred may be used as the medium of instruction depending upon which language is more commonly used and better understood by the pupils.

(c) From the fourth grade, English shall be the medium of instruction provided that Shona or Ndebele shall be taught as subjects on an equal time allocation basis with the English language.

(d) In areas where minority languages exist, the Minister may authorize the teaching of such languages in primary schools in addition to those specified in subsection (a), (b) and (c). 
From these stipulations, it becomes clear that English has the higher status in Zimbabwe's Education Act. It is the most prestigious language, with the African languages being given the lower status. Chitiga (1995) traces this situation back to the early days of the colonization of Zimbabwe, arguing that because it was the colonizer's language, English assumed the most important position in the life of Zimbabweans in all formal spheres like education, commerce and the media.

Since it is taught in all regions, English is placed at the top of the hierarchy, followed by Shona and Ndebele which are instructed in their respective regions, even up to tertiary levels. Minority languages like Shangani are at the bottom of the hierarchy since they are taught only up to grade three. However, it should be noted that Shona and Ndebele used to be taught from ordinary level up to tertiary level through medium of English. It is only since February 2006 when the Zimbabwe School Examination Council (ZIMSEC) sent a circular that English should no longer be used in teaching Shona and Ndebele that this situation has changed.

Apart from being the only publication languages, Shona and Ndebele are given much airtime on national radio stations, while the other recognized minority languages are broadcast on National FM with news slots of only five minutes. Both Shona and Ndebele are also used on this radio station. On National Television, English is given more airtime than any other language. Airtime allotted to English news bulletins ranges from thirty minutes to over an hour during the course of the day while Shona and Ndebele news bulletins are given fifteen minute slots twice daily. Discussions on current affairs are usually presented in English. There are also drama programmes in Shona and Ndebele on National Television. Minority languages like Shangani do not have these privileges.

This shows that there is much that needs to be done for these minority languages. In the case of Shangani, speakers are unable to study their language beyond primary school level in post-colonial Zimbabwe. Minority languages like Shangani have never been examined at any level. In the 1930s and 1940s, Shangani was taught up to standard six at the Lundi Mission School but learners never sat for examinations. It was only in 2004 that the government revised the Zimbabwe Education Act, making provision for the teaching and examination of Shangani and the other five official minority languages at school and tertiary education level. However, the government does not seem to take significant action in promoting the teaching and examination of these languages. There are very few government projects for the development of these languages. The government does not seem to be taking issues of language development seriously, probably because it is occupied with other issues considered of more importance.

Another major problem is the unavailability of written materials for use in schools. The teachers responsible for these languages have to translate either Shona or Ndebele texts. All the minority languages that are taught have no 
standard orthographies. The teachers use diverse orthographies. ALRI has now intervened to improve the Zimbabwean language situation.

\section{ALRI'S role in language education and development}

ALRI is dedicated to researching, documenting, developing and promoting Zimbabwe's indigenous languages. It also aims at promoting the marginalized minority languages, Shangani included. ALRI's chief preoccupation is the compilation of dictionaries in the indigenous languages. So far it has published dictionaries in the two major indigenous languages, Shona and Ndebele.

Compiling a dictionary does not guarantee its proper usage. Dictionaryusing skills must be learnt to appropriately respond to community needs. Users must be made to realize the importance of dictionaries. Also, language use policies facilitating communication between languages need to be in place for dictionaries, especially bilingual ones. If there is no recognition of formal literacy in other languages, there will be general illiteracy in communities speaking the indigenous languages. The following observation from the report of the World Commission on Culture and Development (1995: 57) should be noted:

Minorities often find it difficult to participate fully in the activities of societies that favour dominant groups. Sometimes this discrimination is embedded in the legal framework that denies these minorities access to education, employment and political representation. More generally, however, the lack of participation is less a matter of official policy than of everyday practice. The challenge consists in first removing discriminatory barriers and then creating the basis for the empowerment of these minorities.

From this observation, it becomes clear that the policies denying the rights of minorities in the areas of culture and education, and exerting domination by linguistic and ethic hegemonies, create a state of discrimination and denial of access to self-actualization. To break this vicious circle, this report urged the global community to adopt a vision for the 21st century that would uphold the protection and exercise of cultural rights, especially in education. The development of resources to support these is critical for the survival of minority languages. For Zimbabwe this means that minority languages like Shangani must also be researched, documented, developed and promoted. The following sum up the reasons for and the objectives of the ALRI Shangani dictionary project:

- As dictionaries are increasingly becoming effective tools for storing knowledge and its transmission, and improving language and culture acquisition and appreciation, Shangani lexicographical development will be instrumental to a revival of the language.

- Skilful dictionary use will contribute to better interlanguage communication and more independence and confidence in language learning and 
culture information, especially in the case of Shangani which is spoken as a minority language.

- How well dictionary skills in language and culture communication can be learned will depend on the way the dictionary presents its material. So it is hoped that the dictionary will be the integral text in education in Shangani, and that it will afford learners to explore and appreciate their language.

What ALRI has actually demonstrated with the publication of the Shona and Ndebele dictionaries is that a dictionary has hitherto been an unknown tool for the speakers of these languages. As a tool for storing knowledge about a language and its culture and for supporting literacy and learning, speakers have come to realize the authoritativeness of a dictionary. Speakers of Shona and Ndebele who could never before have been persuaded that they need such a tool, now realize the value of a dictionary. Hopefully Shangani speakers will also see in their dictionary the benefits of developing their language.

There are several challenges to the use of Shangani dictionaries in the Zimbabwean educational system:

- School syllabi are designed by people who have never had formal training in dictionary use: dictionaries are seen as works of reference, only needed when the problem of a word's meaning arises; dictionaries are thought to be confined to learners, who lack fluency in a language; and dictionaries are never thought of as providing any practical skills.

- Unavailability of dictionaries is never felt to be a very serious problem: the language teacher is thought to fulfil the language needs of the pupils and students; and the dictionary is viewed as a luxury so that its place is difficult to define in the teaching-learning process.

- Poor reference skills among teachers and their scholars and students mean that dictionaries remain virtually unemployed in the learningteaching environment, and they may even be thought of as interfering in this process.

The ALRI project in general seeks to correct these misperceptions by presenting the dictionary as a language development tool. Over the years, ALRI researchers have shown that effective dictionary use is fundamental in the domain of social communication. In education, it is essential as a pedagogical tool (Townsend Coles 1988). However, ALRI studies have indicated that there is a general apathy towards dictionaries and a reluctance to their use, that may arise from the teachers' inadequate knowledge of and skills in applying dictionaries in the language class. This apathy and reluctance can also be ascribed to the methods of teaching. Most of the communicative methods used in schools require the deductive approach, where the teacher presents and explains all the material. Also, many language-teaching methods are grammar rather than vocabulary 
oriented, so that a dictionary is consulted only when a specific terminological problem arises in class.

\section{How is ALRI helping in the development of minority languages?}

ALRI now also facilitates the compilation of dictionaries in Zimbabwe's minority languages. Minority mother-tongue speakers are trained to do the required linguistic field work and documentation. Lexicography is used as a step in the development and standardization of these minority languages. Chimhundu (2005) sees the compilation of dictionaries as "a strategy for empowerment of the indigenous language communities in the post-colonial era". He considers lexicography as "the meeting point of all the disciplines that have a bearing on language success in raising the status of a language". Lexicographical research at ALRI is therefore part of the initial efforts to develop and standardize languages which have never been seriously studied before.

\subsection{What is being done now?}

In 2001, ALRI started collecting data for a corpus from Shangani-speaking areas. The collection of Shangani texts is in progress. Mother-tongue Shangani speakers are hired to do fieldwork. They record oral interviews covering different issues of life. These interviews are transcribed by Shangani mothertongue speakers who have some basic linguistic background, using diverging orthographies.

There also is a Shangani reference group which comprises Shangani mother-tongue speakers from all areas where the language is used. From time to time, workshops and seminars are held with this reference group to obtain views on methods of developing the language. Plans are in progress to engage the Ministry of Education, Sport and Culture as well as other interested stakeholders to sample the work that is being done so that there is acceptability of the results.

\subsection{What are the experiences?}

It proves a very difficult task to start with a dictionary of a language in which no previous lexicographical work has been done. Except for the fact that there is no valuable written material in Zimbabwean Shangani, as has been indicated earlier, there is also no orthographic tradition. As a language that has not been well researched, all sorts of grammatical and semantic problems occur. These must all be considered before the actual compilation of the dictionary begins. The greatest challenge faced by ALRI is that of producing a useful dictionary meeting lexicographical standards with the limited available resources as far as personnel, finances and time are concerned. 
A major problem is the lack of staff at ALRI to undertake the compilation of the dictionary. There is only one key person possessing the relevant lexicographical training, who encodes the material written in the diverging orthographies the Shangani mother-tongue speakers use when transcribing the interviews.

Except for the inadequate funding to effectively carry out research, ALRI also does not have suitable transport to use when visiting some of the remote areas for data collecting. Furthermore, there are accessibility problems. Shangani-speaking areas are often undeveloped border areas where there are no road networks. Researchers have to walk long distances when carrying out interviews.

Experience at ALRI has shown that lexicographical work is subject to time pressures. Data collection, data processing, and data capturing are necessary but laborious procedures. For a language such as Shangani that has no valuable written material, the work is greatly hindered by time limits. The fieldworkers undertaking data collection must first employ informants and then check, analyze and systematize the data collected by them so that it can eventually be captured at ALRI.

\subsection{The nature of the Shangani community}

Data collection for corpus expansion is still in progress. The nature of the Shangani community, however, causes problems. This is mainly experienced in some remote areas where the language is spoken. Although mother-tongue speakers, who are fluent in the language do the field work, the interviewees are at times reluctant or uncomfortable to be frank. As a closed community, the Shangani do not want to disclose some of their ways of life, especially some peculiar cultural practices. Fearing exploitation, they still doubt that the work is a genuine linguistic study without any political connotations.

\subsection{The orthography and status of Shangani}

Like other Zimbabwean minority languages, Shangani does not have a standard orthography. There are many divergences and inconsistencies in the material collected for corpus building at ALRI. These orthographic divergences and inconsistencies mainly result from the fact that most of the written material in Zimbabwe's minority languages consist of recordings of oral interviews taken down by fieldworkers or informally composed texts written by literate speakers, both groups using divergent orthographies. There are therefore no standard texts that can be accessed for the sake of reference. Since minority languages were not taught up to higher levels in schools, publishers were unwilling to invest in them because it was unprofitable to do so. With all this in mind, the researchers at ALRI have to find ways of dealing with the issue of the 
Shangani orthography since it is "possible to speak of lexicography only when a writing convention has been developed in a language" (Mathumba 1999: 254). However, language standardization is not a quickly solved issue. There are many channels that need to be followed. Mosel (2002: 3) argues that although the orthographic standardization of a language can be difficult, often being a political matter, it should not retard the compilation and production of a dictionary by incessant debates. What is important is that those concerned should agree on alternative spellings for some words. The decision on which orthography to use will hopefully be arrived at through workshops with the Shangani reference groups as well as other interested stakeholders. Knowledgeable phoneticians and phonologists will be engaged to assist in finding a viable orthographic convention for Shangani. The intention is that the proposed dictionary will become a major normative reference work, which can contribute to developing a standard orthography for Zimbabwean Shangani as well as stimulating the production of more works in and on the language.

Connected to the issue of orthography, is the debate among members of the reference group about the status of Shangani. They are divided on whether to treat Shangani as an independent language from Tsonga or just as a Tsonga dialect. Those who argue that Shangani is a Tsonga dialect feel that it is needless to waste money and resources on issues of standardizing the language. Advocating the harmonization of Shangani and Tsonga spoken in neighbouring countries, they want to adopt the South African or Mozambican Tsonga orthography. However, they agree with those who prefer a unique Zimbabwean orthography, that Shangani now has some peculiar features from Tsonga although they believe that these features can be harmonized. Those who want a different orthography from the Tsonga of neighbouring countries, argue that Shangani is no longer a Tsonga dialect, but an autonomous language with its own dialects.

\subsection{Who will be the users of the dictionary and what kind of dictionary should be planned?}

The dictionary is first and foremost meant for the indigenous Zimbabwean speakers of Shangani. However, it is seen as having an important role in bringing the language on the agenda for modern development.

Mosel (2002: 4) states that compilers should have to be clear on what exactly is the purpose of their dictionary. It is not just enough to have a dictionary in order to document the lexicon of the language for future generations. The compilers of the Shangani dictionary will have to answer such questions as: For whom is the dictionary primarily intended? Should it be bilingual or monolingual? Does the status of Zimbabwean Shangani warrant the compilation of a monolingual dictionary? Should Shangani follow the way of Shona and Ndebele lexicography? All these questions are some of the challenges the researchers are facing. 
The planning and compiling of modern dictionaries demand that specific objectives should be followed. Most important is to identify the dictionary's prospective users and determine the purpose for which it will be used. The answer to this question will also determine what kind of information should be given in the dictionary. So far there is still debate on the type of dictionary to be compiled. There are some who advocate the compilation of a bidirectional Shangani-Shona dictionary while others are for a bidirectional Shangani-English dictionary.

It is argued that since Shangani speakers are found in Shona-speaking areas, a Shangani-Shona dictionary will also help Shona speakers who want to learn Shangani. Since Shangani speakers are a minority, this will also ensure that the dictionary will reach a fairly large number of users.

Those who favour a Shangani-English dictionary base their argument on the fact that such a dictionary will have a much larger number of users than a Shangani-Shona one. This is mainly because speakers of languages like Ndebele will also be able to use it. Actually, all literate people in Zimbabwe will be able to employ it for learning Shangani. The Shangani-English proposal also has a cross-border perspective, because of Shangani being spoken in South Africa and Mozambique too. As a linguistic document, it will indeed add to the mass of lexicological data on African languages already available.

There are also others who feel that the trend at ALRI is the compilation of monolingual dictionaries, so the proposed dictionary should be a monolingual one. But the question with this view is: Does the status of Zimbabwean Shangani in so far as its development is concerned, allow for the compilation of a monolingual dictionary? Should Shangani follow the way of Shona or Ndebele lexicography? Shona and Ndebele lexicography did not just start by compiling monolingual dictionaries. The first dictionaries for both these languages were bilingual ones, English being one of the languages together with Shona and Ndebele. Because of these bilingual dictionaries, they at least had a starting point. Except for this printed material, there were also electronic databases for these languages available. Both Shona and Ndebele were furthermore standardized.

It becomes evident that the challenges of Shangani lexicological development are on all levels, planning, development and publication. For now the focus is on data compilation. It is hoped that with the modern dictionary software that ALRI uses, the final publication will be determined by demand, and will be specifically directed at assisting in the development of other language processes.

\subsection{What kind of dictionary would be possible?}

As has been indicated above, the Shangani project is constrained by limited resources of money, staff and time but it must be organized in such a way that a useful dictionary is produced. With a view to this critical situation, ALRI is 
planning a small comprehensive general Shangani dictionary which aims to meet lexicographical standards. Word lists will be translated from English and Shona. Some will be extracted from a text corpus. The corpus material collected in the documentation project will cover a wide range of different speech situations. However, even with these transferred resources from English and Shona, the work is demanding.

The development of a Shangani dictionary is unique. While historically the priorities of the colonialists for language development did not favour minority ethnic languages, researchers at ALRI are now technically in a better position to creatively and proactively address these issues through a well thought through and scientifically proven process within the promotion policy for the national Zimbabwean languages. In this regard, the following aspects need urgent attention:

(a) Dictionaries compiled of languages selected for the cultural systems development are essential as they can be instrumental in reviving the linguistic and cultural resources of any ethnic community.

(b) The development of ethnic languages with the aid of a dictionary will ensure the positive democratization and promotion of social equity and harmony in education, and indeed mutual respect among all ethnic groups, facilitating cultural appreciation and sharing by speech communities.

(c) The dictionary as a storehouse of cultural, or ethno-cultural knowledge should underscore the fundamental need to facilitate the speech community to fully attain access to all its linguistic and cultural expressions.

(d) An appropriate compilation of commercializable dictionaries will make the neighbouring communities reach their inner soul, and indeed enhance their cultural values even across borders.

The completion of the first Shangani dictionary will set the basis and the pace for these accomplishments.

\section{Conclusion}

The facts behind the dictionary development issues within ALRI that may arise when debating the need for an integrative and ethnic-directed cultural policy have been dealt with. These have been raised within the broader issues of the language rights to education of marginalized ethnic communities (cf. Townsend Coles 1988), and, most important, the democratic rights of all citizens to express their culture and also to be taught in their own languages, and indeed at such a level as will be deemed appropriate for the national interests (UNESCO 1997). Although the discourse and debate over these issues have often been sensationalized and controversialized by intellectuals and politicians, 
mainly in the state bureaucracies, ALRI has chosen a way that will guarantee a producible dictionary even with meagre means.

Undertaking the lexicographical development of Shangani will entail greater justification for its inclusion in the education system of Zimbabwe, at least at elementary levels. Indeed, the lexicographical product will enhance literacy development on at least two levels: orthography and vocabulary. Dictionary resources are therefore very important for minority languages. However, from the discussion, it is evident that there are many factors with which to grapple, chief among them being the financial ones. Human resources can be more easily provided for if the means are available.

\section{References}

Chimhundu, H. 2005. Lexicography and Language Raising. Public lecture presented as part of the Golden Jubilee Celebrations of the University of Zimbabwe, Harare, 13 April 2005.

Chitiga, M. 1995. Codeswitching in the Classroom. Unpublished M.A. Thesis. Harare: University of Zimbabwe.

Hachipola, J.S. 1998. A Survey of the Minority Languages of Zimbabwe. Harare: University of Zimbabwe Publications.

Mathumba, D.I. 1999. The State of Xitsonga Lexicography. Lexikos 9: 254-257.

Mosel, Ulrike. 2002. Dictionary Making in Endangered Speech Communities. Wittenburg, P., W. Peters and S Drude (Eds.). 2002. Proceedings of the Third International Conference on Language Resources and Evaluation (LREC2002), Workshop on Tools and Resources in Field Linguistics, University of Las Palmas de Gran Canaria, 26-27 May 2002. Paris: European Languages Resources Association.

Townsend Coles, E.K. 1988. Let the People Learn. Manchester: University of Manchester.

UNESCO. 1997. CONFINTEA. Adult Education. The Hamburg Declaration. The Agenda for the Future. Hamburg: UNESCO.

Viriri, A. 2003. Language Planning: The Conservation and Management of Indigenous Languages in Zimbabwe. Unpublished paper presented at the ICOMOS 14th General Assembly and Scientific Symposium held at Victoria Falls, Zimbabwe, 27-31 October 2003.

World Commission on Culture and Development. 1995. Our Creative Diversity. Paris: UNESCO.

Zimbabwe Constitution. 1987. Zimbabwe Education Act of 1987, Chapter 55.

Zimbabwe School Examination Council (ZIMSEC). 2006. Circular of February 2006. 